\title{
An investigation of the mechanism of inhibition of the $\mathrm{Ca}^{2+}$-ATPase by phospholamban
}

\author{
Glen HUGHES*, Anthony P. STARLING, Ram P. SHARMA, J. Malcolm EAST and Anthony G. LEE $\dagger$ \\ Department of Biochemistry, University of Southampton, Southampton S016 7PX, U.K.
}

The $\mathrm{Ca}^{2+}$-ATPase of skeletal muscle sarcoplasmic reticulum has been reconstituted with peptides corresponding to the hydrophobic domain of phospholamban (PLB) with or without the three Cys residues replaced by Ala, and with PLB with the three Cys residues replaced by Ala $\left[\operatorname{PLB}^{\mathrm{Cys}-}(1-52)\right]$. Reconstitution with the hydrophobic domain of PLB [PLB(25-52)] was found to decrease the apparent affinity of the ATPase for $\mathrm{Ca}^{2+}$ with no effect on the maximal rate of ATP hydrolysis observed at saturating concentrations of $\mathrm{Ca}^{2+}$. Reconstitution with $\mathrm{PLB}^{\mathrm{Cys}-}(1-52)$ decreased both the apparent affinity for $\mathrm{Ca}^{2+}$ and the maximal activity; the effect on maximal activity followed from a decrease in the rate of the $\mathrm{Ca}^{2+}$ transport step $\left(\mathrm{E} 1 \mathrm{PCa}_{2} \rightarrow\right.$ E2P) as observed with the hydrophilic domain PLB(1-25). The concentration dependences of the effects of the hydrophobic domain and of the whole PLB molecule were very similar, suggesting that the hydrophilic domain made little contribution to the affinity of the ATPase for PLB. The effect of PLB on the ATPase was dependent on the molar ratio of phospholipid to ATPase, suggesting partition of the PLB between its binding site on the ATPase and the bulk lipid phase in the membrane. Neither PLB nor its hydrophobic domain affected the rates of phosphorylation or dephosphorylation of the ATPase. Despite their effects on the apparent affinity of the ATPase for $\mathrm{Ca}^{2+}$, neither PLB nor its hydrophobic domain had any effect on the true affinity of the ATPase for $\mathrm{Ca}^{2+}$, as measured from changes in the tryptophan fluorescence of the ATPase. The effects of PLB on the activity of the ATPase are the sum of the effects of its hydrophilic and hydrophobic domains.

\section{INTRODUCTION}

The activity of the $\mathrm{Ca}^{2+}$-ATPase in cardiac muscle sarcoplasmic reticulum ( $\mathrm{SR}$ ) is modulated by interaction with a small (52 residues) membrane-bound protein, phospholamban (PLB). The structure predicted for PLB consists of a hydrophilic N-terminal domain (Met-1 to Asn-30) linked to a hydrophobic C-terminal domain (Leu-31 to Leu-52), likely to be a transmembrane $\alpha$ helix. The hydrophilic domain contains two regions, an $\mathrm{N}$ terminal region from Met-1 to Pro-21, predicted to be $\alpha$-helical, and a less structured region (Asn-22 to Asn-30) linking the Nterminal region to the transmembrane $\alpha$-helix [1-5]. PLB, when unphosphorylated, binds to the ATPase and inhibits it; phosphorylation of PLB by $\mathrm{Ca}^{2+} /$ calmodulin-dependent or cAMP-dependent protein kinases leads to the expression of full ATPase activity, presumably as a result of dissociation of PLB from the ATPase [1].

Binding of PLB to the $\mathrm{Ca}^{2+}$-ATPase in cardiac $\mathrm{SR}$ reduces the apparent affinity of the ATPase for $\mathrm{Ca}^{2+}$ (determined from plots of $\mathrm{Ca}^{2+}$ uptake rate as a function of $\mathrm{Ca}^{2+}$ concentration) [6-10]. It is unclear whether or not PLB also causes a decrease in the maximal activity of the ATPase measured at saturating concentrations of $\mathrm{Ca}^{2+}$. Some studies have reported a $20 \%$ decrease in the maximal rate of accumulation of $\mathrm{Ca}^{2+}$ by cardiac SR vesicles [6-8,11], whereas others have reported no effect [12-15]. This contrasts with the $40-45 \%$ decrease in ATPase activity seen on binding the hydrophilic domain of PLB to the purified cardiac [16] or skeletal muscle $\mathrm{Ca}^{2+}$-ATPase [17]. We have shown that the smaller and variable results seen when measuring $\mathrm{Ca}^{2+}$ accumulation might arise from the complexity of the uptake assay, performed in the presence of oxalate, where different results can be obtained depending on how the data are analysed [18]. However, it is important to demonstrate that the effect of the hydrophilic domain of PLB is the same whether or not it is anchored to the membrane by the hydrophobic domain.

For detailed kinetic studies it is more convenient to use the sarcoplasmic/endoplasmic-reticulum $\mathrm{Ca}^{2+}$-ATPase 1 (SERCA1) isoform of the $\mathrm{Ca}^{2+}$-ATPase found in skeletal muscle SR than the SERCA2 isoform found in cardiac SR because only the former can be readily purified in the quantities required for reconstitution with PLB. When the skeletal muscle $\mathrm{Ca}^{2+}$-ATPase is reconstituted with PLB $[1,19,20]$ or when it is co-expressed with PLB in COS or $\mathrm{C}_{2} \mathrm{C}_{12}$ cells $[21,22]$, inhibition of ATPase activity is observed, as for the cardiac $\mathrm{Ca}^{2+}$-ATPase. A major binding site for PLB on the cardiac $\mathrm{Ca}^{2+}$-ATPase has been identified between Asp-370 and Lys-400, a region that is highly conserved between the SERCA1 and SERCA2 isoforms [23].

Here we report a study of the effects of PLB and of the hydrophobic domain of PLB on the pre-steady-state kinetics of skeletal muscle $\mathrm{Ca}^{2+}$-ATPase; Sasaki et al. [16] found that the hydrophobic domain of PLB decreased the affinity of the cardiac $\mathrm{Ca}^{2+}$-ATPase for $\mathrm{Ca}^{2+}$ with no effect on the maximum rate. For

Abbreviations used: DOPC, dioleoylphosphatidylcholine; E1, E2, different enzyme forms; E2P, enzyme-phosphate complex; NBD, 7-nitro-2,1,3benzoxadiazole; PLB, rabbit heart phospholamban; PLB(1-25), a peptide corresponding to residues 1-25 of PLB; PLB(25-52), a peptide corresponding to residues 25-52 of PLB; PLB ${ }^{\text {Cys- }}(1-52)$, a peptide corresponding to PLB, with Cys residues at positions 36,41 and 46 replaced by Ala; PLB ${ }^{\text {Cys-}}{ }^{-}$(25-52), a peptide corresponding to residues 25-52 of PLB, with Cys residues at positions 36 , 41 and 46 replaced by Ala; SERCA, sarcoplasmic/endoplasmic-reticulum $\mathrm{Ca}^{2+}$-ATPase; SR, sarcoplasmic reticulum.

* Present address: Department of Biochemistry, University of Leeds, Leeds LS2 9JT, U.K.

$\uparrow$ To whom correspondence should be addressed. 


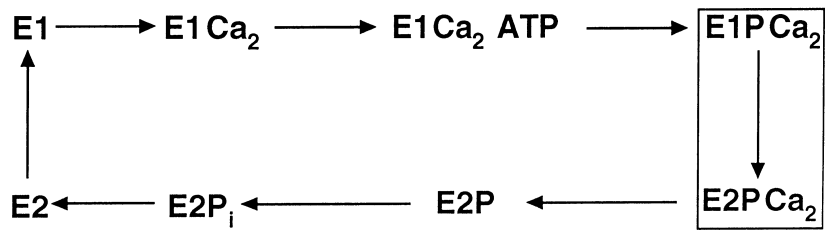

Scheme 1 Simplified reaction scheme for the $\mathrm{Ca}^{2+}$-ATPase

these studies we have synthesized a mutant PLB (PLB ${ }^{\mathrm{Cys}-}$ ) in which the three Cys residues in the transmembrane domain (residues 36, 41 and 46) [24] were replaced with Ala. PLB has been shown to form very stable pentamers; mutation of the Cys residues has been shown to prevent pentamer formation with no effect on the interaction with the ATPase [25,26].

The kinetics of the ATPase are usually discussed in terms of the E1-E2 model shown in Scheme 1, although recent experiments have cast doubt on the existence of two distinct forms of the phosphorylated ATPase $\left(\mathrm{E} 1 \mathrm{PCa}_{2}\right.$ and $\left.\mathrm{E} 2 \mathrm{PCa}_{2}\right)$ [27]. It is proposed that in the E1 conformation the ATPase possesses two outward-facing $\mathrm{Ca}^{2+}$ binding sites of high affinity. After binding of $\mathrm{Ca}^{2+}$ and ATP the enzyme is phosphorylated and undergoes a conformation change to $\mathrm{E} 2 \mathrm{PCa}_{2}$ from which $\mathrm{Ca}^{2+}$ is lost to the lumen of the SR. Dephosphorylation of E2P allows recycling to E1.

\section{MATERIALS AND METHODS}

\section{Materials}

Dioleoylphosphatidylcholine (DOPC) was purchased from Avanti Polar Lipids, Inc. (Birmingham, AL, U.S.A.). Sarcoplasmic reticulum and purified $\mathrm{Ca}^{2+}$-ATPase were prepared from rabbit skeletal muscle [28]. Concentrations of ATPase were estimated by using the specific extinction coefficient (1.2 litre $\cdot \mathrm{g}^{-1} \cdot \mathrm{cm}^{-1}$ for a solution in $1 \%$ SDS) given by Hardwicke and Green [29].

A mutant form of rabbit heart PLB, PLB $^{\mathrm{Cys}-}(1-52)$ was synthesized in which the three Cys residues were replaced by Ala residues; the peptide was $\mathrm{N}$-acetylated. The peptide was synthesized manually by using F-moc (9-fluorenylmethoxycarbonyl) chemistry [30] on a 2-chlorotrityl chloride resin [31]. The peptide was cleaved from the solid support with acetic acid/trifluoroethanol/dichloromethane $(1: 2: 7$, by vol.) and purified by reversephase HPLC on a C18 Vydac column with a $0-80 \%(\mathrm{v} / \mathrm{v})$ acetonitrile gradient containing $0.1 \%(\mathrm{v} / \mathrm{v})$ trifluoroacetic acid. The peptide was freeze-dried and then deprotected with a mixture of trifluoroacetic acid/anisole/ethanedithiol (38:1:1, by vol.). The peptide was precipitated by the addition of diethyl ether and then further washed with diethyl ether. It was characterized by laser desorption mass spectrometry (Perceptive Biosystems) in a matrix of sinapinic acid or $\alpha$-cyano-4-hydroxycinnamic acid, giving a single peak of the expected molecular mass. The transmembrane peptide $\mathrm{PLB}^{\mathrm{Cys}-}(25-52)$ was prepared in the same way.

The peptide PLB(25-52) containing the three Cys residues at positions 36, 41 and 46 was synthesized by t-Boc (t-butyloxycarbonyl) chemistry with Merrifield resin [32]. The peptide was deprotected and cleaved from the resin with HF by standard procedures [32]. The crude peptide was purified and characterized as described above.

SDS/PAGE was used to determine the aggregation state of PLB $^{\text {Cys- }}$ (1-52). Gels were run as described by Laemmli [33] with a $7-18 \%(\mathrm{w} / \mathrm{v})$ gradient of polyacrylamide in the running gel and $3 \%(\mathrm{w} / \mathrm{v})$ polyacrylamide in the stacking gel.

\section{Reconstitution with PLB}

DOPC and PLB were mixed in the required molar ratio in chloroform/methanol $(2: 1, \mathrm{v} / \mathrm{v})$ containing a few drops of trifluoroacetic acid to dissolve the PLB. An aliquot of the mixture, typically containing $10 \mu \mathrm{mol}$ of phospholipid, was dried to a thin film under vacuum. It was then sonicated to clarity in buffer $[400 \mu 1 ; 10 \mathrm{mM}$ Hepes/Tris, $\mathrm{pH} 8.0$, containing $15 \%$ (w/v) sucrose, $5 \mathrm{mM} \mathrm{MgSO}_{4}$ and $12 \mathrm{mg} / \mathrm{ml}$ potassium cholate] in a bath sonicator. ATPase $(1.25 \mathrm{mg})$ in a volume of $20-30 \mu \mathrm{l}$ was then added and the mixture left for $15 \mathrm{~min}$ at room temperature and $45 \mathrm{~min}$ at $5{ }^{\circ} \mathrm{C}$ to equilibrate. For rapid-quench experiments, after equilibration the samples were added to precooled Oakridge tubes containing ice-cold buffer $(10 \mathrm{mM}$ Hepes/Tris, $\mathrm{pH} 8.0,2 \mathrm{mM}$ dithiothreitol) and centrifuged at $200000 \mathrm{~g}$ for $1 \mathrm{~h} \mathrm{at} 4{ }^{\circ} \mathrm{C}$. Samples were rehomogenized and suspended in buffer [10 mM Hepes/Tris, pH 8.0, $15 \%(\mathrm{w} / \mathrm{v})$ sucrose] to a concentration of $3-8 \mathrm{mg} / \mathrm{ml}$, and stored at $-20^{\circ} \mathrm{C}$ until use. For steady-state kinetic and rapid filtration experiments, samples after equilibration were diluted directly into the appropriate assay media as described below. Reconstitutions with PLB(25-52) were performed in the same way.

\section{ATPase assay}

ATPase activities were determined at $25^{\circ} \mathrm{C}$ by using a coupled enzyme assay in a medium containing $40 \mathrm{mM}$ Hepes $/ \mathrm{KOH}$, $\mathrm{pH} 7.2,100 \mathrm{mM} \mathrm{KCl}, 5 \mathrm{mM} \mathrm{MgSO}_{4}, 2.1 \mathrm{mM}$ ATP, $1.1 \mathrm{mM}$ EGTA, $0.41 \mathrm{mM}$ phosphoenolpyruvate, $0.15 \mathrm{mM}$ NADH, 7.5 units of pyruvate kinase and 18 units of lactate dehydrogenase in a total volume of $2.5 \mathrm{ml}$. The reaction was initiated by the addition of an aliquot of a $25 \mathrm{mM} \mathrm{CaCl}_{2}$ solution to a cuvette containing the ATPase and the other reagents, to give the required concentration of $\mathrm{Ca}^{2+}$. Free concentrations of $\mathrm{Ca}^{2+}$ were calculated by using the binding constants for $\mathrm{Ca}^{2+}, \mathrm{Mg}^{2+}$ and $\mathrm{H}^{+}$ to EGTA given by Godt [34].

\section{Rapid kinetic experiments}

The time dependence of phosphorylation-induced $\mathrm{Ca}^{2+}$ release from the ATPase was determined with a Biologic Rapid filtration system [17] and the time dependences of phosphorylation of the ATPase by $\left[\gamma_{-}{ }^{32} \mathrm{P}\right]$ ATP and of dephosphorylation of the ATPase phosphorylated with $\left[{ }^{32} \mathrm{P}\right] \mathrm{P}_{\mathrm{i}}$ in the absence of $\mathrm{Ca}^{2+}$, or with $[\gamma-$ $\left.{ }^{32} \mathrm{P}\right] \mathrm{ATP}$ in the presence of $\mathrm{Ca}^{2+}$, were determined with a Biologic QFM-5 system as described by Starling et al. [35].

\section{Fluorescence experiments}

The ATPase was labelled with 7-nitro-2,1,3-benzoxadiazole (NBD) as described [36]. Measurements of NBD and tryptophan fluorescence were performed at $25^{\circ} \mathrm{C}$ using an SLM Aminco $8000 \mathrm{C}$ fluorimeter. NBD fluorescence was recorded with excitation and emission wavelengths of 430 and $520 \mathrm{~nm}$, respectively, and tryptophan fluorescence was recorded with excitation and emission wavelengths of 290 and $340 \mathrm{~nm}$, respectively.

\section{RESULTS}

\section{Reconstitution of the ATPase with PLB $^{\text {Cys- }}(1-52)$}

A mutant PLB, PLB ${ }^{\mathrm{Cys}-}(1-52)$, in which the Cys residues were replaced by Ala, was synthesized by using F-moc chemistry on a 


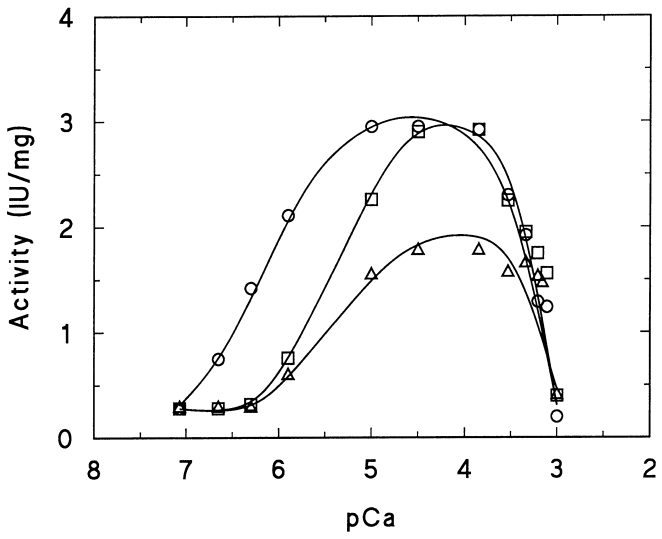

Figure 1 Effects of PLB ${ }^{\text {Cys- }}(1-52)$ and PLB(25-52) on ATPase activity

Shown are the ATPase activities [units (IU)/mg of protein] for the ATPase alone $(O)$ or after reconstitution with $\mathrm{PLB}^{\mathrm{Cys}-}(1-52)(\triangle)$ or $\mathrm{PLB}(25-52)(\square)$; for the reconstituted systems the molar ratios of peptide/added lipid/ATPase were 100:2000:1. ATPase activities were measured at $\mathrm{pH} 7.2$ with $2.1 \mathrm{mM}$ ATP and the given concentration of $\mathrm{Ca}^{2+}$, at $25^{\circ} \mathrm{C}$.

Barlos resin [31]. The side-chain-protected peptide was cleaved from the resin by treatment with $0.1 \%(\mathrm{v} / \mathrm{v})$ trifluoroacetic acid and purified by HPLC while the side chains were still protected. Side chain protection was then removed by treatment with $90 \%$ (v/v) trifluoroacetic acid. A peptide $\mathrm{PLB}^{\mathrm{Cys}-}(25-52)$ was prepared in the same way, corresponding to the transmembrane domain (residues 25-52) of PLB, again with the three Cys residues replaced by Ala. Finally, a peptide PLB(25-52), corresponding to the transmembrane domain but containing the three Cys residues, was prepared by using t-BOC chemistry on a Merrifield resin [32].

The hydrophobicity of $\mathrm{PLB}^{\mathrm{Cys}-}(1-52)$ and of the transmembrane domains PLB(25-52) and $\operatorname{PLB}^{\mathrm{Cys}-}(25-52)$ meant that they had to be incorporated into membrane systems by reconstitution. We determined the success of reconstitution by measuring the shift in the $\mathrm{Ca}^{2+}$ dependence of ATPase activity, as described below. In previous studies we have shown that the ATPase can be reconstituted with phospholipids by dissolving the ATPase and lipid in cholate, followed by dilution into buffer to decrease the concentration of cholate below its critical micelle concentration [37]. Attempts to reconstitute the ATPase and $\mathrm{PLB}^{\mathrm{Cys}-}(1-52)$ by simply dissolving $\mathrm{PLB}^{\mathrm{Cys}-}(1-52)$ in cholate followed by mixing with the ATPase in cholate gave very small effects on activity. However, if $\mathrm{PLB}^{\mathrm{Cys}-}(1-52)$ was first mixed with DOPC in organic solvent, dried down to form a thin film and then dissolved in cholate, good reconstitutions were achieved, as shown by large effects on the $\mathrm{Ca}^{2+}$-dependence of activity. The molar ratio of DOPC to $\mathrm{PLB}^{\mathrm{Cys}-}(1-52)$ in the initial mixture was found to be important. At molar ratios of DOPC to peptide of less than 10:1, reconstitution was inefficient; in most of the experiments reported here, a molar ratio of DOPC to peptide of 20:1 was employed.

Figure 1 shows the effects of $\mathrm{PLB}^{\mathrm{Cys}-}(1-52)$ and $\mathrm{PLB}(25-52)$ on ATPase activity as a function of $\mathrm{Ca}^{2+}$ concentration measured at a peptide/DOPC/ATPase molar ratio of 100:2000:1. Both $\mathrm{PLB}^{\mathrm{Cys}-}(1-52)$ and $\mathrm{PLB}(25-52)$ increased the concentration of $\mathrm{Ca}^{2+}$ giving $50 \%$ maximal activity from a pCa of 6.2 to 5.5 ; PLB $^{\text {Cys- }}(1-52)$ also caused a $40 \%$ decrease in maximal ATPase activity. Neither peptide affected the decrease in ATPase activity observed at high concentrations of $\mathrm{Ca}^{2+}$. The shift in $\mathrm{pCa}$ for $50 \%$ activation of the ATPase and the decrease in maximal

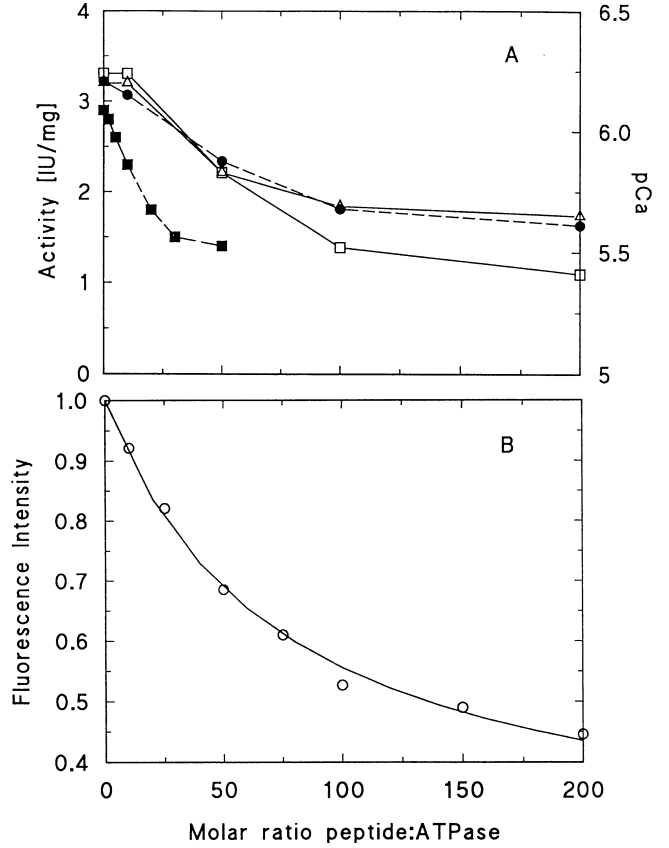

Figure 2 Effects of molar ratios of peptide to ATPase on the activity and tryptophan fluorescence intensity of the ATPase

(A) Shifts in pCa values giving $50 \%$ maximal activity $(\square, \triangle)$ and maximal ATPase activities (-口) are plotted for the ATPase reconstituted with $\operatorname{PLB}^{\text {Cys-}}(1-52)(\triangle, \triangle)$ or $\operatorname{PLB}^{\text {Cys }}-(25-52)(\square)$ at a fixed molar ratio of added lipid to ATPase of $2000: 1$ or at a fixed molar ratio of lipid to $\mathrm{PLB}^{\mathrm{Cys}-}(1-52)$ of 10:1 ( $\left.\mathbf{\square}\right)$. (B) The ATPase was reconstituted with PLB(25-52) at the given molar ratios of peptide to ATPase, at a molar ratio of DOPC to ATPase of 2000:1. Fluorescence was measured with excitation and emission wavelengths of 290 and $340 \mathrm{~nm}$ respectively, in $50 \mathrm{mM}$ Hepes/Tris, pH 7.2, containing $0.3 \mathrm{mM}$ EGTA

activity are plotted as a function of the molar ratio of peptide to ATPase in Figure 2(A). As shown, effects are maximal at a molar ratio of peptide to ATPase of 100:1 when the molar ratio of DOPC to ATPase was maintained constant at 2000:1. When the same experiment was repeated by reconstitution with a 10:1 molar ratio of DOPC to $\mathrm{PLB}^{\mathrm{Cys}-}(1-52)$ (so that the total amount of lipid in the system varied), the effect of the peptide saturated at a molar ratio of $\mathrm{PLB}^{\mathrm{Cys}-}(1-52)$ to ATPase of $30: 1$. Thus the amount of peptide required to produce maximal effects increased as the amount of lipid in the system increased.

We have shown that Cys-containing peptides can quench the fluorescence of the ATPase labelled with a variety of fluorescence probes [38]. Figure 2(B) shows the effect of PLB(25-52) on the intensity of the tryptophan fluorescence of the ATPase, as a function of the molar ratio of peptide to ATPase at a fixed molar ratio of DOPC to ATPase of 2000:1. As shown, the results fit to a simple binding curve, with a maximum quenching of $78 \%$, the half-maximal quenching being observed at a molar ratio of peptide to lipid of $74 \pm 8$ (S.E.). The results are very similar to those observed in activity plots under comparable conditions (Figure 2A).

\section{Mechanism of inhibition of the ATPase by PLB ${ }^{\text {Cys- }}(1-52)$}

We have shown that melittin and myotoxin inhibit the $\mathrm{Ca}^{2+}$ ATPase by decreasing the rate of dephosphorylation of the phosphorylated ATPase [38,39]. The rate of dephosphorylation can be determined either by first phosphorylating the ATPase with $\left[{ }^{32} \mathrm{P}\right] \mathrm{P}_{\mathrm{i}}$ at $\mathrm{pH} 6.0$ in the absence of $\mathrm{Ca}^{2+}$ and the presence of 


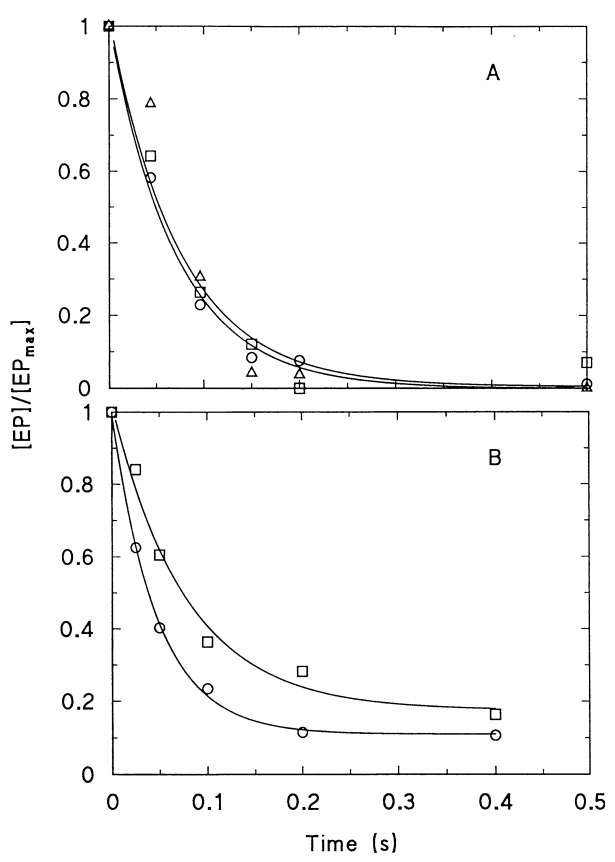

Figure 3 Effect of $\mathrm{PLB}^{\mathrm{Cys}-}(1-52)$ on the rate of dephosphorylation of the ATPase

The results show rates of dephosphorylation for the ATPase $(O)$ or the ATPase reconstituted with PLB ${ }^{C y s}-(1-52)$ at a molar ratio of peptide/DOPC/ATPase of 100:2000:1 ( $\square$ ). (A) The enzyme syringe contained ATPase ( $4 \mathrm{mg} / \mathrm{ml}$ protein) in $12.5 \mathrm{mM}$ Mes/Tris, pH 6.0, containing $10 \mathrm{mM}$ EGTA, $\left.1 \mathrm{mM}{ }^{32} \mathrm{P}\right] \mathrm{P}_{\mathrm{i}}, 20 \mathrm{mM} \mathrm{Mg}{ }^{2+}$ and $14 \%$ (v/v) DMSO. The second syringe contained $100 \mathrm{mM}$ Mes/Tris, pH 7.5, $100 \mathrm{mM} \mathrm{KCl}, 4 \mathrm{mM} \mathrm{Mg}{ }^{2+}$ and $5.3 \mathrm{mM}$ ATP. The contents of the enzyme syringe were mixed in a 1:16 volume ratio with the dephosphorylation mixture and the reaction quenched at the given times with $25 \%(\mathrm{w} / \mathrm{v})$ trichloroacetic acid. Also shown is the rate of dephosphorylation measured in the same way in the presence of $20 \mu \mathrm{M}$ $\operatorname{PLB}(1-25)(\triangle)$. (B) The enzyme syringe contained ATPase $(0.2 \mathrm{mg} / \mathrm{ml}$ protein) in $20 \mathrm{mM}$ $\mathrm{Mes} / \mathrm{Tris}, \mathrm{pH} 7.2,5 \mathrm{mM} \mathrm{Mg}^{2+}, 100 \mathrm{mM} \mathrm{KCl}$ and $100 \mu \mathrm{M} \mathrm{Ca}^{2+}$. This was mixed in a $1: 1$ ratio with a solution containing $50 \mu \mathrm{M}\left[\gamma_{-}{ }^{32} \mathrm{P}\right]$ ATP in the same buffer. The mixture was incubated for $20 \mathrm{~ms}$, then mixed in a 1:1 ratio with the same buffer containing $2.5 \mathrm{mM}$ unlabelled ATP. The reaction was quenched at the given time with $25 \%$ (w/v) trichloroacetic acid. The solid lines show fits to single-exponential processes with the rates given in the text.

DMSO followed by mixing with an excess of a $\mathrm{pH} 7.5$ buffer containing $\mathrm{KCl}$ and ATP to induce dephosphorylation, or by first phosphorylating the ATPase with $\left[\gamma_{-}{ }^{32} \mathrm{P}\right] \mathrm{ATP}$ in the presence of $\mathrm{Ca}^{2+}$ and then mixing with an excess of unlabelled ATP. The rate of dephosphorylation measured in the absence of $\mathrm{Ca}^{2+}$ is unaffected by the presence of either PLB ${ }^{\mathrm{Cys}-}(1-52)$ or a peptide corresponding to the hydrophilic domain $[\mathrm{PLB}(1-25)]$, the rates ( \pm S.E.) being $14.3 \pm 1.6 \mathrm{~s}^{-1}$ in the absence of peptide and $13.6 \pm 2.8$ and $11.1 \pm 3.5 \mathrm{~s}^{-1}$ in the presence of $\mathrm{PLB}^{\mathrm{Cys}-}(1-52)$ and $\mathrm{PLB}(1-25)$ respectively (Figure $3 \mathrm{~A})$. In contrast, the rate $( \pm$ S.E.) of dephosphorylation of the ATPase phosphorylated with ATP decreases from $21.4 \pm 0.9$ to $12.9 \pm 2.3 \mathrm{~s}^{-1}$ after reconstitution with $\mathrm{PLB}^{\mathrm{Cys}-}(1-52)$ (Figure $\left.3 \mathrm{~B}\right)$. An effect on the rate of dephosphorylation measured in the presence of $\mathrm{Ca}^{2+}$ but not in its absence would be consistent with a change in the rate of the $\mathrm{Ca}^{2+}$ transport step. This was confirmed by direct measurement. For the ATPase in either the absence or the presence of $\mathrm{PLB}^{\mathrm{Cys}-}(1-52)$, the rate of phosphorylation of the ATPase by ATP is much faster than the rate of dissociation of ${ }^{45} \mathrm{Ca}^{2+}$ from the unphosphorylated ATPase (see below). Orlowski and Champeil [40] have shown that under these conditions the rate of $\mathrm{Ca}^{2+}$ dissociation from the phosphorylated ATPase (the E1PCa $\rightarrow$ E2P step in Scheme 1) can be measured by pre-equilibrating the ATPase with ${ }^{45} \mathrm{Ca}^{2+}$

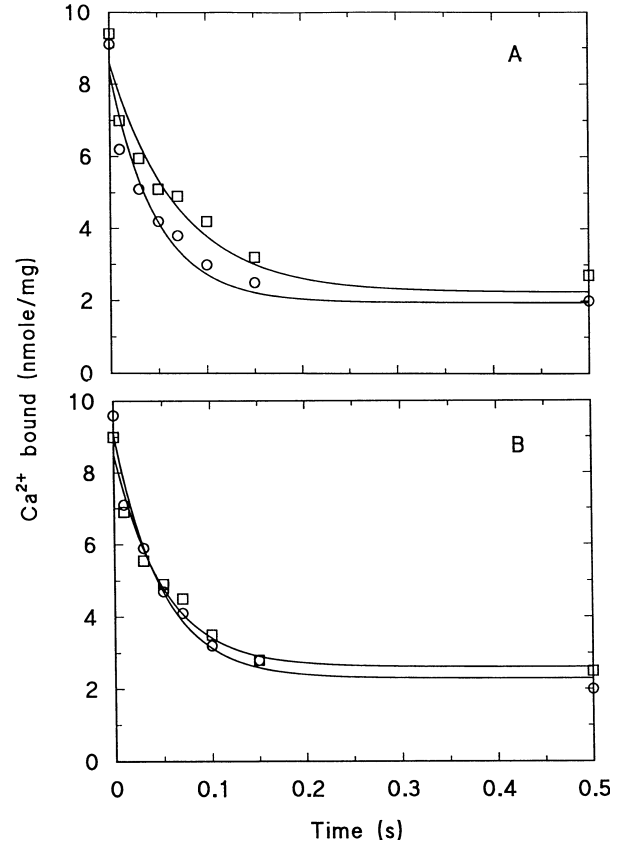

Figure 4 The effect of PLB ${ }^{\text {Cys- }}(1-52)$ and PLB(25-52) on the rate of ATPinduced release of ${ }^{45} \mathrm{Ca}^{2+}$ from the ATPase

The figure shows results with the ATPase $(O)$ or the ATPase reconstituted with PLB $^{\text {Cys }-(1-52)}$ (A) or PLB(25-52) (B), at a molar ratio of peptide/DOPC/ATPase of 100:2000:1 ( $\square$ ). ATPase $(0.4 \mathrm{mg} / \mathrm{ml})$ was first equilibrated in $\mathrm{pH} 7.2$ buffer $(20 \mathrm{mM}$ Hepes/Tris, $100 \mathrm{mM} \mathrm{KCl}, 20 \mathrm{mM}$ $\mathrm{Mg}^{2+}$ ) containing $100 \mu \mathrm{M}^{45} \mathrm{Ca}^{2+}$ and $\left.0.5 \mathrm{mM} \mathrm{[}{ }^{3} \mathrm{H}\right]$ sucrose and then $0.1 \mathrm{mg}$ of ATPase was adsorbed on Millipore filters. The loaded filter was perfused for the given times with the same buffer containing $100 \mu \mathrm{M}$ unlabelled $\mathrm{Ca}^{2+}$ and $2 \mathrm{mM}$ ATP. The lines show fits to singleexponential processes with the rate constants given in the text.

and then perfusing it on Millipore filters with ${ }^{40} \mathrm{Ca}^{2+}$ and ATP. Dissociation of ${ }^{45} \mathrm{Ca}^{2+}$ from the ATPase measured under these conditions fitted to single-exponential processes with rate constants $( \pm$ S.E. $)$ of $21.1 \pm 4.5$ and $14.2 \pm 6.3 \mathrm{~s}^{-1}$ in the absence or presence of $\mathrm{PLB}^{\mathrm{Cys}-}(1-52)$ respectively (Figure 4A). PLB(25-52) had no effect on the rate of the $\mathrm{Ca}^{2+}$ transport step under the same conditions: the observed dissociation of ${ }^{45} \mathrm{Ca}^{2+}$ fitted to rate constants $( \pm$ S.E. $)$ of $20.9 \pm 3.5$ and $20.0 \pm 3.6 \mathrm{~s}^{-1}$ in the absence and presence of PLB(25-52) respectively (Figure 4B).

The rate of phosphorylation of the ATPase was unaltered by reconstitution with $\mathrm{PLB}^{\mathrm{Cys}-}(1-52)$; the time courses of phosphoenzyme formation fitted to single-exponential processes with rates of $87 \pm 14$ and $102 \pm 3 \mathrm{~s}^{-1}$ for the ATPase in the absence or presence of $\mathrm{PLB}^{\mathrm{Cys}-}(1-52)$ respectively, at a molar ratio of peptide/DOPC/ATPase of 100:2000:1 (results not shown).

\section{Effects on apparent $\mathrm{Ca}^{2+}$ affinity}

Binding of $\mathrm{Ca}^{2+}$ to the high-affinity binding sites on the ATPase can be monitored by observation of the resulting changes in tryptophan fluorescence intensity [41-44]. The pCa giving a halfmaximal fluorescence change was 6.43 for the ATPase reconstituted with DOPC and 6.38 in the presence of $\operatorname{PLB}(25-52)$ at a peptide/DOPC/ATPase molar ratio of 100:2000:1 (Figure 5A). Similarly, $\mathrm{PLB}^{\mathrm{Cys}-}(1-52)$ had no significant effect on $\mathrm{Ca}^{2+}$ affinity, with $\mathrm{pCa}$ values for half-maximal fluorescence changes of 5.54 and 5.64 in the absence and presence of $\operatorname{PLB}^{\mathrm{Cys}-}(1-52)$ respectively, in the presence of $20 \mathrm{mM} \mathrm{Mg}^{2+}$ (Figure 5B). These results agree with those of Cantilina et al. [10] and show that PLB 


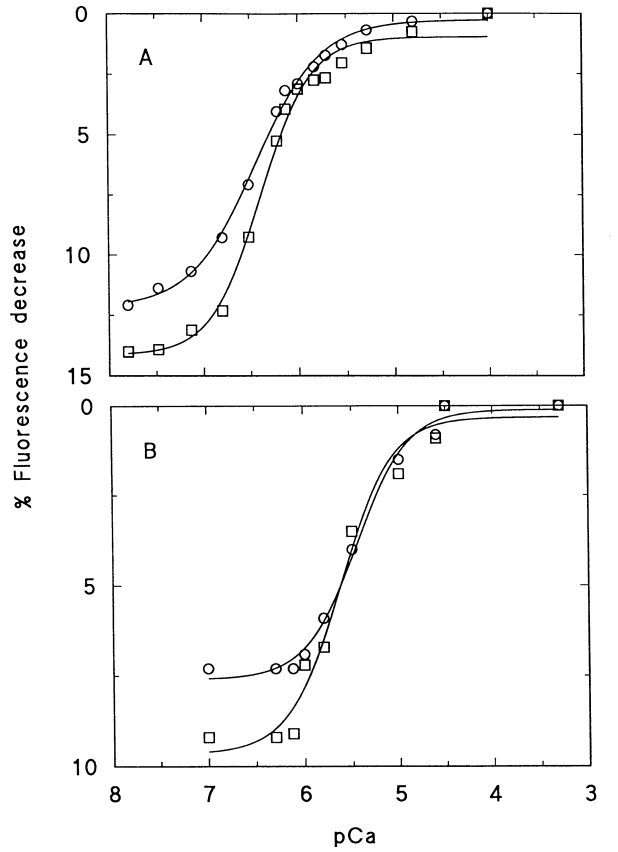

Figure $5 \mathrm{Ca}^{2+}$ dependence of tryptophan fluorescence intensity

The figure shows the percentage decrease in tryptophan fluorescence intensity of the ATPase $(0.7 \mu \mathrm{M})$ on addition of EGTA to the given pCa value in (A) $20 \mathrm{mM}$ Hepes/ $\mathrm{KOH}$, pH 7.2, $100 \mathrm{mM} \mathrm{KCl}, 1 \mathrm{mM} \mathrm{CaCl}$, or (B) $50 \mathrm{mM}$ Mops/KOH, pH 7.2, $100 \mathrm{mM} \mathrm{KCl}, 20 \mathrm{mM} \mathrm{Mg}^{2+}$, $1 \mathrm{mM} \mathrm{CaCl}$, in the absence $(O)$ or presence $(\square)$ of peptide at a molar ratio of peptide/DOPC/ATPase of 100:2000:1. (A) PLB(25-52); (B) PLB ${ }^{\text {Cys- }}$ (1-52). Fluorescence was excited at $290 \mathrm{~nm}$ and observed at $340 \mathrm{~nm}$.

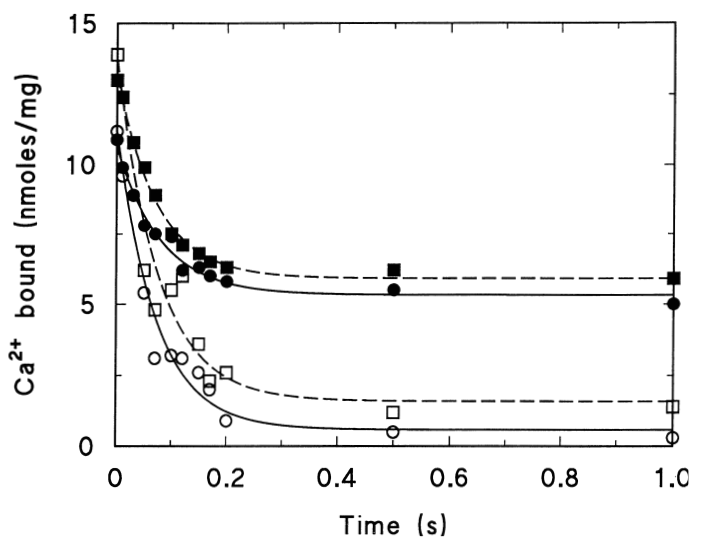

Figure 6 Effect of PLB(25-52) on the rate of dissociation of ${ }^{45} \mathrm{Ca}^{2+}$ from the ATPase

The figure shows the dissociation of ${ }^{45} \mathrm{Ca}^{2+}$ when the ATPase incubated in buffer $(20 \mathrm{mM}$ Hepes/KOH, pH 7.2) containing $100 \mathrm{mM} \mathrm{KCl}, 20 \mathrm{mM} \mathrm{Mg}^{2+}$ and $100 \mu \mathrm{M}^{45} \mathrm{Ca}^{2+}$ was perfused with the same buffer containing either $2 \mathrm{mM} \mathrm{EGTA}(O, \square)$ or $1 \mathrm{mM}^{40} \mathrm{Ca}^{2+}(\mathbf{)})$ in the absence $(\bigcirc, \mathbf{O})$ or presence $(\square, \boldsymbol{\square})$ of PLB(25-52) at a molar ratio of peptide/lipid/ATPase of $100: 2000: 1$. The lines show fits to single-exponential decays as described in the text.

has no effect on equilibrium $\mathrm{Ca}^{2+}$ binding to the ATPase in the absence of ATP, despite the decrease in apparent $\mathrm{Ca}^{2+}$ affinity found in kinetic studies (Figure 1).

Effects of PLB(25-52) on the rate of $\mathrm{Ca}^{2+}$ dissociation from the ATPase were studied by using the method of rapid filtration. On washing ${ }^{45} \mathrm{Ca}^{2+}$-bound ATPase with EGTA, essentially all

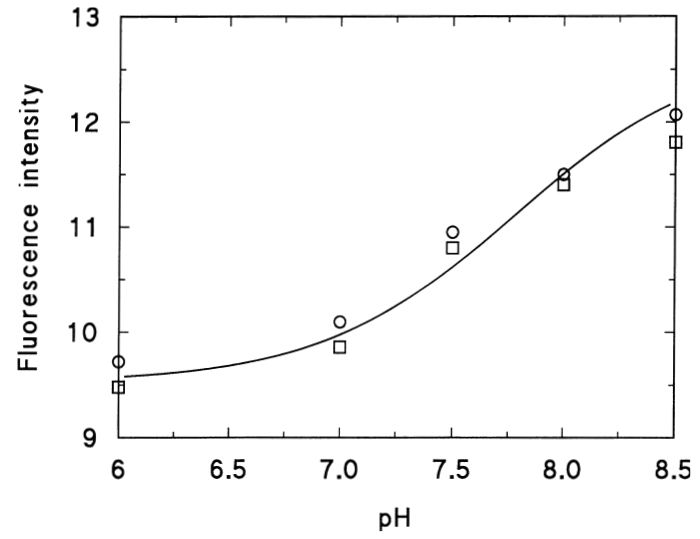

Figure 7 Effect of $\mathrm{pH}$ and PLB(25-52) on the fluorescence intensity of NBD-labelled ATPase

Shown are the fluorescence intensities of NBD-labelled ATPase in the absence $(O)$ or presence ( $\square$ ) of PLB(25-52) at a molar ratio of peptide/lipid/ATPase of 100:2000:1. The lines are simulations of the data, calculated from the parameters in Henderson et al. [44] with fluorescence intensities for the E1 and E2 conformations of 13.5 and 9.5 respectively. Buffers were as follows: pH 6.0/6.5, $50 \mathrm{mM}$ Mes/Tris; pH 7.0/7.5, $50 \mathrm{mM}$ Hepes/Tris; pH 8.0/8.5, $50 \mathrm{mM}$ Tris/Mes. All buffers contained $0.3 \mathrm{mM}$ EGTA.

the bound ${ }^{45} \mathrm{Ca}^{2+}$ is lost from the ATPase, the results fitting to a single-exponential process with rates $( \pm$ S.E.) of $14.0 \pm 2.2$ and $13.3 \pm 2.6 \mathrm{~s}^{-1}$ in the absence and presence of $\operatorname{PLB}(25-52)$ respectively (Figure 6). On washing with $1 \mathrm{mM}^{40} \mathrm{Ca}^{2+}$ only half the ${ }^{45} \mathrm{Ca}^{2+}$ is lost; the dissociation of $\mathrm{Ca}^{2+}$ fitted to a singleexponential process with rates $( \pm$ S.E.) of $12.6 \pm 1.5$ and $13.8 \pm 0.9 \mathrm{~s}^{-1}$ in the absence and presence of $\operatorname{PLB}(25-52)$ respectively (Figure 6).

Effects of PLB(25-52) on the E2-E1 equilibrium of the ATPase were studied by making use of the conformational sensitivity of the ATPase labelled with NBD $[45,46]$. The fluorescence emission intensity of NBD-labelled ATPase increases with increasing $\mathrm{pH}$, consistent with proton-binding constants of $5 \times 10^{5}$ and $3.0 \times 10^{8} \mathrm{M}^{-1}$ for $\mathrm{E} 1$ and $\mathrm{E} 2$ respectively, with an equilibrium constant E1/E2 of 4.0 for the non-protonated forms [44]. In previous studies we have shown that binding to NBD-labelled ATPase of PLB(1-25) results in an increase in fluorescence intensity, consistent with stronger binding of $\operatorname{PLB}(1-25)$ to the E1 than to the E2 conformation of the ATPase [17]. Reconstitution with $\mathrm{PLB}(25-52)$ has no significant effect on the fluorescence intensity of NBD-labelled ATPase, suggesting that it has no effect on the E1/E2 equilibrium (Figure 7).

\section{DISCUSSION}

An analogue of PLB was synthesized in which the three Cys residues in the transmembrane domain were replaced with Ala. This prevented pentamer formation by PLB in the membrane, without affecting the interaction between PLB and the ATPase $[25,26]$; SDS/PAGE of PLB $^{\mathrm{Cys}-}(1-52)$ showed no trace of a pentameric species (results not shown). $\operatorname{PLB}^{\mathrm{Cys}-}(1-52)$ was reconstitituted with the ATPase by premixing $\mathrm{PLB}^{\mathrm{Cys}-}(1-52)$ and lipid in organic solvent at a molar ratio of lipid to peptide of at least $10: 1$, followed by removal of solvent before solubilization in cholate and mixing with the ATPase. Under these conditions, large effects of $\mathrm{PLB}^{\mathrm{Cys}-}(1-52)$ both on the $\mathrm{Ca}^{2+}$ dependence of ATPase activity and on maximal activity are observed (Figure 1). The shift in $\mathrm{Ca}^{2+}$ concentration giving $50 \%$ maximal activity is comparable to that reported for the effect of PLB in cardiac SR 
(pCa shifts of $0.3-0.5 ;[6-8,10,47]$ ) and is greater than that reported with other methods of reconstitution [13].

The concentration dependence of the effect of $\mathrm{PLB}^{\mathrm{Cys}-}(1-52)$ depends on the molar ratio of lipid to ATPase. For the ATPase reconstituted with $\mathrm{PLB}^{\mathrm{Cys}-}(1-52)$ at a fixed molar ratio of DOPC to ATPase of 2000:1, the maximal effect of $\mathrm{PLB}^{\mathrm{Cys}-}(1-52)$ is observed at a molar ratio of $\mathrm{PLB}^{\mathrm{Cys}-}(1-52)$ to ATPase of approx. 100:1 (Figure 2). When the ATPase is reconstituted with a $10: 1$ molar ratio of lipid to $\mathrm{PLB}^{\mathrm{Cys}-}(1-52)$ and the total amount of lipid in the system is not held constant, the maximal effect of $\mathrm{PLB}^{\mathrm{Cys}-}(1-52)$ is observed at a molar ratio of $\mathrm{PLB}^{\mathrm{Cys}-}(1-52)$ to ATPase of $30: 1$, corresponding to a molar ratio of DOPC to ATPase of $300: 1$. These results suggest a relatively weak interaction between $\mathrm{PLB}^{\mathrm{Cys}-}{ }^{-}(1-52)$ and the ATPase, so that PLB $^{\mathrm{Cys}-}(1-52)$ partitions between the ATPase and the bulk lipid phase of the membrane. The observed similar concentration dependences of the effects of $\mathrm{PLB}^{\mathrm{Cys}-}(1-52)$ and $\mathrm{PLB}^{\mathrm{Cys}-}(25-52)$ on the $\mathrm{Ca}^{2+}$ dependence of ATPase activity (Figure 2) suggest that the hydrophilic domain of PLB contributes little to the affinity of PLB for the ATPase; this is consistent with the observed weak binding $\left(K_{\mathrm{d}} 5 \mu \mathrm{M}\right)$ of PLB $(1-25)$ to the ATPase $[16,17]$. The similarity between the fluorescence quenching profiles for PLB(25-52) and for the effects of $\mathrm{PLB}^{\mathrm{Cys}-}(25-52)$ on ATPase activity (Figure 2) suggest both that the effects of the hydrophobic domain follow directly from binding to the ATPase (rather than being mediated indirectly, for example through a change in the properties of the lipid component of the membrane) and that binding to the ATPase is little affected by mutation of the three Cys residues in the transmembrane domain.

The molar ratios of PLB to ATPase required to produce maximal inhibition of the ATPase in reconstituted systems are considerably higher than the molar ratio of PLB to ATPase found in cardiac SR, estimated to be approx. 2-2.5:1 [9]. Beekman et al. [48] have shown that the molar ratio of PLB to ATPase is higher in hypothyroid than in normal animals, and that the effect of phosphorylation of PLB by protein kinase A is correspondingly also greater in the hypothyroid animals. These experiments therefore suggest that the molar ratio of PLB to ATPase found in normal animals is lower than that required to produce maximal inhibition of the ATPase. Presumably the requirement to reduce the inhibitory effects of PLB by phosphorylation means that the physiologically optimal concentration of PLB in the membrane is not the high concentration that would be required to produce maximal inhibition. At a molar ratio of DOPC to ATPase of 100:1, PLB at a 10:1 molar ratio of PLB to ATPase results in a decrease in $\mathrm{pCa}$ for halfmaximal stimulation of the $\mathrm{Ca}^{2+}$-ATPase of approx. 0.6, comparable to the effects of PLB observed in cardiac SR (see, for example, [10]). Thus the molar ratio of PLB to ATPase required to give a given effect in the reconstituted system is about 4-fold higher than that in cardiac SR. This is likely to be partly due to the higher molar ratios of lipid to ATPase in the reconstituted system. Further, in the reconstituted system, ATPase molecules are randomly incorporated into the two faces of the bilayer and the distribution of PLB across the membrane is also probably random; this might then halve the effective concentration of PLB in the membrane. Finally, the distribution of PLB within the reconstituted system might not be homogeneous; an inhomogeneous distribution of PLB would, however, not be important for the studies reported here on the maximal effects of PLB on the ATPase.

Our results show that the effects of PLB on the ATPase are the sum of the effects of its hydrophilic and hydrophobic domains. The hydrophilic domain of PLB decreases the maximal activity of the ATPase, with no effect on $\mathrm{Ca}^{2+}$ affinity [16,17]; we have shown that inhibition follows from a decrease in the rate of the $\mathrm{Ca}^{2+}$ transport step $\left(\mathrm{E} 1 \mathrm{PCa}_{2} \rightarrow \mathrm{E} 2 \mathrm{P}\right.$ in Scheme 1) [17]. $\mathrm{PLB}^{\mathrm{Cys}-}(1-52)$ also decreased the rate of this step by $33 \%$ whereas PLB(25-52) had no effect (Figure 4). We therefore conclude that the hydrophilic domain on PLB can bind to the ATPase and inhibit the $\mathrm{Ca}^{2+}$ transport step, either as a watersoluble peptide or as part of the intact PLB molecule anchored to the membrane by its hydrophobic domain. The structure of PLB in the membrane must therefore be such as to allow access of the hydrophilic domain of PLB to its binding site on the cytoplasmic domain of the $\mathrm{Ca}^{2+}$-ATPase.

Neither $\mathrm{PLB}^{\mathrm{Cys}-}(1-52)$ nor PLB(25-52) had any affect on the rate of phosphorylation of the ATPase by ATP (results not shown); in previous studies we have shown that $\operatorname{PLB}(1-25)$ also had no effect on the rate of phosphorylation [17]. PLB ${ }^{\mathrm{Cys}-}(1-52)$ also had no effect on the equilibrium level of phosphorylation of the ATPase by $\mathrm{P}_{\mathrm{i}}$ at $\mathrm{pH} 6.2$ (results not shown) or on the rate of dephosphorylation of the ATPase phosphorylated by $P_{i}$ in the absence of $\mathrm{Ca}^{2+}$ (Figure 3A). The observed decrease in the rate of dephosphorylation of the ATPase phosphorylated by ATP in the presence of $\mathrm{Ca}^{2+}$ (Figure 3B) can be attributed to the decrease in the rate of the $\mathrm{Ca}^{2+}$ transport step $\mathrm{E} 1 \mathrm{PCa}_{2} \rightarrow \mathrm{E} 2 \mathrm{P}$ (Figure 4).

Whereas PLB(1-25) had no effect on the $\mathrm{Ca}^{2+}$ dependence of ATPase activity [17], PLB $^{\mathrm{Cys}-}(1-52)$ and PLB(25-52) decreased the apparent $\mathrm{Ca}^{2+}$ affinities by similar amounts (Figure 1). It is therefore clear that it is interaction between the hydrophobic domain of PLB and the ATPase that results in a decrease in the apparent affinity. These results agree with those of Sasaki et al. [16], who showed that PLB(28-47) decreased the apparent affinity of cardiac $\mathrm{Ca}^{2+}$-ATPase with no effect on maximal rates.

Cantilina et al. [10], using an anti-PLB antibody to dissociate PLB from the ATPase in cardiac SR vesicles, have shown that equilibrium $\mathrm{Ca}^{2+}$ binding to the ATPase is unaffected by PLB, despite the shift in apparent affinity observed in activity assays. This is confirmed for the reconstituted system by using tryptophan fluorescence to monitor $\mathrm{Ca}^{2+}$ binding to the ATPase; neither PLB ${ }^{\mathrm{Cys}-}(1-52)$ nor PLB(25-52) had any effect on the $\mathrm{Ca}^{2+}$ affinity (Figure 5). As described by Cantilina et al. [10], effects of PLB on the apparent $\mathrm{Ca}^{2+}$ affinity are then likely to follow from effects on the rates of the steps involved in $\mathrm{Ca}^{2+}$ binding to the ATPase. We therefore studied the effects of PLB(25-52) on the rate of $\mathrm{Ca}^{2+}$ dissociation from the ATPase. However, as shown in Figure 6, no significant effects were observed on these rates. PLB(25-52) also had no effect on the equilibrium constant E1/E2 (Figure 7). It is therefore possible that the effects of PLB on the rates of the $\mathrm{Ca}^{2+}$-binding steps occur only in the presence of ATP, which is known to affect the rates of some of these steps [50].

We thank the BBSRC for financial support and for a studentship to $G$. $H$.

\section{REFERENCES}

1 Tada, M. (1992) Ann. N.Y. Acad. Sci. 671, 92-103

2 Arkin, I. T., Rothman, M., Ludlam, C. F. C., Aimoto, S., Engelman, D. M., Rothschild, K. J. and Smith, S. 0. (1995) J. Mol. Biol. 248, 824-834

3 Mortishire-Smith, R. J., Pitzenberger, S. M., Burke, C. J., Middaugh, C. R., Garsky, V. M. and Johnson, R. G. (1995) Biochemistry 34, 7603-7613

4 Tatulian, S. A., Jones, L. R., Reddy, L. G., Stokes, D. L. and Tamm, L. K. (1995) Biochemistry 34, 4448-4456

5 Alvarez-Coque, M. G., Hernandez, M. J. M., Camanas, R. M. V. and Fernandez, C. M. (1989) Anal. Biochem. 178, 1-7

6 Kirchberger, M. A., Borchman, D. and Kasinathan, C. (1986) Biochemistry 25 , 5484-5492

7 Lu, Y. Z. and Kirchberger, M. A. (1994) Biochemistry 33, 5056-5062

8 Kimura, Y., Inui, M., Kadoma, M., Kijima, Y., Sasaki, T. and Tada, M. (1991) J. Mol. Cell Cardiol. 23, 1223-1230 
9 Colyer, J. and Wang, J. H. (1991) J. Biol. Chem. 266, 17486-17493

10 Cantilina, T., Sagara, Y., Inesi, G. and Jones, L. R. (1993) J. Biol. Chem. 268, 17018-17025

11 Kim, H. W., Steenaart, N. A., Ferguson, D. G. and Kranias, E. G. (1990) J. Biol. Chem. 265, 1702-1709

12 Voss, J., Jones, L. R. and Thomas, D. D. (1994) Biophys. J. 67, 190-196

13 Reddy, L. G., Jones, L. R., Cala, S. E., Obrian, J. J., Tatulian, S. A. and Stokes, D. L. (1995) J. Biol. Chem. 270, 9390-9397

14 Morris, G. L., Cheng, H. C., Colyer, J. and Wang, J. H. (1991) J. Biol. Chem. 266 $11270-11275$

15 Sham, J. S., Jones, L. R. and Morad, M. (1991) Am. J. Physiol. 261, H1344-H1349

16 Sasaki, T., Inui, M., Kimura, Y., Kuzuya, T. and Tada, M. (1992) J. Biol. Chem. 267, 1674-1679

17 Hughes, G., East, J. M. and Lee, A. G. (1994) Biochem. J. 303, 511-516

18 Starling, A. P., Hughes, G., Sharma, R. P., East, J. M. and Lee, A. G. (1995) Biochem. Biophys. Res. Commun. 215, 1067-1079

19 Szymanska, G., Kim, H. W., Cuppoletti, J. and Kranias, E. G. (1990) Membr. Biochem. 9, 191-202

20 Vorherr, T., Chiesi, M., Schwaller, R. and Carafoli, E. (1992) Biochemistry 31, $371-376$

21 Toyofuku, T., Kurzydlowski, K., Tada, M. and MacLennan, D. H. (1993) J. Biol. Chem. 268, 2809-2815

22 Harrer, J. M. Ponniah, S., Ferguson, D. G. and Kranias, E. G. (1995) Mol. Cell. Biochem. 146, 13-21

23 James, P., Inui, M., Tada, M., Chiesi, M. and Carafoli, E. (1989) Nature (London) 342, 90-92

24 Fujii, J., Zarainherzberg, A., Willard, H. F., Tada, M. and MacLennan, D. H. (1991) J. Biol. Chem. 266, 11669-11675

25 Fujii, J., Maruyama, K., Tada, M. and MacLennan, D. H. (1989) J. Biol. Chem. 264 12950-12955

26 Toyofuku, T., Kurzydlowski, K., Tada, M. and MacLennan, D. H. (1994) J. Biol. Chem. 269, 3088-3094

27 Myung, J. and Jencks, W. P. (1994) Biochemistry 33, 8775-8785

28 East, J. M. and Lee, A. G. (1982) Biochemistry 21, 4144-4151

Received 29 April 1996/30 May 1996; accepted 10 June 1996
29 Hardwicke, P. M. and Green, N. M. (1974) Eur. J. Biochem. 42, 183-193

30 Atherton, E. and Sheppard, R. C. (1989) Solid Phase Peptide Synthesis: A Practical Approach, IRL Press, Oxford

31 Barlos, K., Chatzi, O., Gatos, D. and Stavropoulos, G. (1991) Int. J. Pept. Protein Res. 37, 513-520

32 Barany, G. and Merrifield, R. B. (1980) in Peptides 2 (Gross, E. and Meienhofer, J., eds.), pp. 1-280, Academic Press, New York

33 Laemmli, U.K. (1970) Nature (London) 227, 680-685

34 Godt, R. E. (1974) J. Gen. Physiol. 63, 722-739

35 Starling, A. P., Hughes, G., East, J. M. and Lee, A. G. (1994) Biochemistry 33 3023-3031

36 Wictome, M., Henderson, I. M. J., Lee, A. G. and East, J. M. (1992) Biochem. J. 283, 525-529

37 Warren, G. B., Toon, P. A., Birdsall, N. J., Lee, A. G. and Metcalfe, J. C. (1974) Biochemistry 13, 5501-5507

38 Baker, K. J., East, J. M. and Lee, A. G. (1995) Biochem. J. 307, 571-579

39 Baker, K. J., East, J. M. and Lee, A. G. (1995) Biochemistry 34, 3596-3604

40 Orlowski, S. and Champeil, P. (1991) Biochemistry 30, 11331-11342

41 Dupont, Y. and Leigh, J. B. (1978) Nature (London) 273, 396-398

42 Fernandez-Belda, F., Kurzmack, M. and Inesi, G. (1984) J. Biol. Chem. 259, 9687-9698

43 Orlowski, S. and Champeil, P. (1991) Biochemistry 30, 352-361

44 Henderson, I. M. J., Khan, Y. M., East, J. M. and Lee, A. G. (1994) Biochem. J. 297 $615-624$

45 Wakabayashi, S., Ogurusu, T. and Shigekawa, M. (1990) Biochemistry 29 10613-10620

46 Wictome, M., Michelangeli, F., Lee, A. G. and East, J. M. (1992) FEBS Lett. 304 $109-113$

47 Tada, M., Ohmori, F., Yamada, M. and Abe, H. (1979) J. Biol. Chem. 254, 319-326

48 Beekman, R. E., van Hardeveld, C. and Simonides, W. S. (1989) Biochem. J. 259 $229-236$

49 Brady, G. W., Fein, D. B., Harder, M. E., Spehr, R. and Meissner, G. (1981) Biophys. J. 34, 13-34

50 Gould, G. W., East, J. M., Froud, R. J., McWhirter, J. M., Stefanova, H. I. and Lee, A. G. (1986) Biochem. J. 237, 217-227 